\title{
Sleep, vigilance, and thermosensitivity
}

\author{
Nico Romeijn • Roy J. E. M. Raymann • Els Møst • Bart Te Lindert • \\ Wisse P. Van Der Meijden • Rolf Fronczek • German Gomez-Herrero • \\ Eus J. W. Van Someren
}

Received: 10 August 2011 /Revised: 9 October 2011 / Accepted: 10 October 2011 / Published online: 3 November 2011

(C) The Author(s) 2011. This article is published with open access at Springerlink.com

\begin{abstract}
The regulation of sleep and wakefulness is well modeled with two underlying processes: a circadian and a homeostatic one. So far, the parameters and mechanisms of additional sleep-permissive and wake-promoting conditions have been largely overlooked. The present overview focuses on one of these conditions: the effect of skin temperature on the onset and maintenance of sleep, and alertness. Skin temperature is quite well suited to provide the brain with information on sleep-permissive and wakepromoting conditions because it changes with most if not all of them. Skin temperature changes with environmental heat and cold, but also with posture, environmental light, danger, nutritional status, pain, and stress. Its effect on the
\end{abstract}

This article is published as part of the Special Issue on Sleep.

N. Romeijn • R. J. E. M. Raymann • E. Møst • B. Te Lindert

G. Gomez-Herrero • E. J. W. Van Someren $(\bowtie)$

Department of Sleep \& Cognition, Netherlands Institute for

Neuroscience, an Institute of the Royal Netherlands Academy of

Arts and Sciences,

Meibergdreef 47,

1105 BA, Amsterdam, The Netherlands

e-mail: e.van.someren@nin.knaw.nl

URL: http://www.nin.knaw.nl/research_groups/van_someren_group/

R. J. E. M. Raymann • E. Møst

Department of Brain, Body and Behavior, Philips Research,

Eindhoven, The Netherlands

W. P. Van Der Meijden • R. Fronczek

Department of Neurology, Leiden University Medical Centre, Leiden, The Netherlands

E. J. W. Van Someren

Department of Integrative Neurophysiology, Center for

Neurogenomics and Cognitive Research, VU University,

Amsterdam, The Netherlands brain may thus moderate the efficacy by which the clock and homeostat manage to initiate or maintain sleep or wakefulness. The review provides a brief overview of the neuroanatomical pathways and physiological mechanisms by which skin temperature can affect the regulation of sleep and vigilance. In addition, current pitfalls and possibilities of practical applications for sleep enhancement are discussed, including the recent finding of impaired thermal comfort perception in insomniacs.

Keywords Sleep · Vigilance · Circadian rhythm . Homeostatic regulation - Thermoregulation .

Thermosensitivity $\cdot$ Insomnia

\section{Introduction}

In order to provide an intuitive idea on the focus of the present review on sleep and thermoregulation, one may try to imagine two situations likely familiar to most researchers and clinicians reading this review. The first situation is as follows. Consider a moment of considerable fatigue after a long working day while there is still that one manuscript that needs to be read and commented on today. What would be the best strategy to promote alertness and finish the job: reading it sitting at one's desk, or rather lying down on the sofa to give in somewhat to the fatigue, and read it semisupine? The second situation is also familiar to many of us. Imagine flying back home from a demanding conference, eager to catch a nap. How does trying to sleep in a sitting position compare to trying to sleep in a supine position? For most of us, answers to these questions come without even the slightest bit of doubt. If one has to stay awake, chances to do so successfully are better with sitting, and even more so with standing, as compared to lying down $[13,14,18$, 
49]. If one desires to sleep on the other hand, most of us succeed much better when lying down [2, 62]. Although most sleep researchers agree with these answers, are they supported by current models on the regulation of sleep and alertness?

\section{Sleep regulation: are a clock and an hourglass sufficient?}

As discussed in detail in other papers in the present special issue and reviewed many times before, the core model of sleep-wake regulation consists of a circadian component and a homeostatic component $[7,19,22]$. The circadian ( circa $=$ about, dies $=$ day) component refers to the clock of the brain. The central clock of our brain is located in the hypothalamic suprachiasmatic nucleus (SCN) and drives many physiological and behavioral rhythms including the promotion of sleep during one part of the circadian cycle and wakefulness during the other part [59], in humans respectively night and day. However, circadian processes are not limited to the central circadian pacemaker formed by the SCN. Indeed, molecular clock mechanisms are found in every single cell (reviewed in [21]). This is not surprising given the fact that the evolution of life on our rotating planet has always occurred in an environment with near-24$\mathrm{h}$ cycles of light and darkness, and corresponding higher and lower environmental temperatures. Given this origin, it is also not surprising that both light and temperature can affect clock mechanisms at the cellular and systems level, as will be touched upon later [21,84].

The homeostatic component refers to the hourglass of the brain. The longer we are awake, the stronger the pressure for sleep. While we are asleep, this pressure dissipates, and as soon as we wake up, the process starts all over again, just like turning an hourglass at every transition between sleep and wakefulness $[1,53,88]$. The neurobiological mechanisms underlying the hourglass are not characterized as well as the mechanisms of the clock are. As reviewed elsewhere in the present special issue and several times before, important roles have been assigned to adenosine [66], to an increase in synaptic density during wakefulness [79], and to cytokines [50].

Back to our question: how does the consensus model of sleep regulation account for the quite familiar experience that it is easier to stay awake in an upright position and easier to fall asleep in a supine position? Does this simple change of posture phase-shift our clock? Does it tilt the hourglass? Does it affect these processes at all? The answer seems to be a definitive no. The clock and hourglass model has brought us very far in understanding the regulation of sleep and wakefulness. Both components are necessary to understand the maintenance and transitions of states. They model it so well under comfortable, safe, and variancelimiting laboratory conditions that we tend to forget that the model may not necessarily be sufficient for a complete understanding of the maintenance and transitions of states, as we will argue below.

\section{Sleep-permissive and wake-promoting conditions}

In real life, sleep onset and maintenance also depend on whether some seemingly trivial yet crucial conditions are met, like having attained an appropriate posture. Being in a supine position is being in a sleep-permissive condition, whereas being upright is being in a wake-promoting condition $[2,13,14,18,49,62]$. Posture is just one of several examples of permissive and promoting conditions. Are we as likely to maintain the state of sleep or wakefulness in a brightly lit versus dark environment [80]? And whatever state the clock and hourglass tells our sleep-regulating systems to implement, how easy are we going to fall asleep, or continue to sleep, in case of acute cold $[65,75]$, heat $[37,63]$, danger $[16,35]$, pain $[26,52]$, or stress [3, 92]? Just like the clock mechanisms are strongly rooted in evolution, so are the sensitivities to sleep-permissive and wake-promoting conditions: the odds for survival would be severely compromised if these were not effective. We plea that insights into the parameters and mechanisms of sleep-permissive and wake-promoting conditions are no less important for our understanding of sleep regulation and sleep disorders than insights into the mechanisms underlying the clock and hourglass are.

The present overview focuses on one of these conditions: the effect of skin temperature on the onset and maintenance of sleep, and alertness. Skin temperature is quite well suited to provide the brain with information on sleep-permissive and wake-promoting conditions because it changes with most if not all of them. Because the skin is rather poikilotherm, its temperature changes with environmental heat and cold. It changes also with posture [61, 78], environmental light $[12,80]$, anxiety [51], nutritional status [48], pain [36, 42, 54], and stress [72]. Its effect on the brain may thus moderate the efficacy by which the clock and homeostat manage to initiate or maintain sleep or wakefulness.

\section{Skin temperature}

Skin temperature is modulated by environmental and endogenous processes. The human skin is under the influence of environmental temperature. In addition, skin temperature depends on endogenous central and autonomic nervous system processes that actively regulate blood flow 
through the skin (reviewed in [43]). Variation in perfusion of the skin with the $\sim 37^{\circ} \mathrm{C}$ blood thus results in an endogenous modulation of skin temperature. Information on skin temperature, measured with cold and warm receptors and conveyed through thermosensitive afferent pathways, reaches the brain in order to allow for thermoregulation [38]. However, information on skin temperature does not only reach brain areas with a primary involvement in thermoregulation but also brain areas involved in other functions (reviewed in [83]).

\section{Skin temperature and sleep-wake regulation}

Indeed, several neuronal systems that are directly or indirectly involved in sleep-wake regulation are sensitive to temperature (reviewed in [84-86]). This is not surprising from an evolutionary perspective given that environmental temperature has a long history of affecting sleep-wake behavior. In the evolutionary older ectotherms, the behavioral relationship between temperature and vigilance level is relatively straightforward. Ectotherms require warming up by exposure to the radiation of the sun in order to become active. On the other hand, endotherms aim to maintain their core body temperature within a small range, which makes the relationship between temperature and vigilance more complex. The most studied organisms, humans and small furred mammals (such as rats, ground squirrels, and hamsters), mainly sleep during that part of the day when their core body temperature is low, and are most awake during the part of the day when their core body temperature is high, which resembles the behavior of ectotherms. But unlike ectotherms, their skin temperature is elevated during the sleep period due to an increase in skin blood flow in combination with behavior that limits heat loss through insulation by creating a warm microclimate, like covering and curling up. This results in an inverse relationship between core and skin temperature in everyday life, while in ectotherms, skin and core body temperature covary over time in phase. The question thus becomes more complicated: to what extent are the biological systems that are involved in sleep-wake rhythm regulation differentially affected by the normal variations in core temperature versus skin temperature?

As extensively reviewed elsewhere [83], several brain areas involved in sleep regulation are differentially sensitive to the local brain temperature which covaries with core temperature, versus skin temperature which shows an inverse relation to core temperature during the 24-h cycle. A key area that plays a key role in both sleep and temperature regulation is the preoptic area of the anterior hypothalamus. Animal studies indicate that both mild local warming of the area using a micro-thermode as well as mild skin warming using a wrap induce its neuronal fire patterns to resemble those of sleep and inhibit those associated with wakefulness $[4,57,58]$. The same was shown in the posterior hypothalamic area. Mild skin warming has also been associated with sleep-like activity in the cerebral cortex and midbrain reticular formation. Local brain warming has furthermore been shown to induce sleep-like firing patterns in the diagonal band but also wake-like firing patterns in the midbrain reticular formation and midline thalamic nuclei. A detailed description of the neuroanatomical pathways involved in the effect of skin temperature on vigilance regulation is beyond the scope of the present paper, and has been reviewed previously [83]. Taken together, the effect of a mild increase in brain temperature may differentially drive different brain areas towards either a more sleep-like or a more wake-like firing pattern. The complex relationship between brain temperature and neuronal firing patterns makes an unequivocal sleep-promoting effect of mild increases in brain temperature unlikely. In contrast, the effect of a mild increase in skin temperature in general seemed to drive different brain areas towards more sleep-like firing patterns. If these findings can be translated to a real-life situation, a mild increase in skin temperature might promote sleep.

Next to these general functional anatomy considerations, how would core and skin temperature affect the specific functional anatomy that underlies the hourglass and clock of sleep regulation? Little is known on specific effects of temperature on the incompletely understood regulation of adenosine that is thought to be involved in the homeostatic aspect of sleep regulation. With respect to the much better understood clock-related systems, evidence has accumulated over the last decade to indicate that peripheral oscillators, including those in the brain (e.g., cerebral cortex), can be entrained by ambient temperature cycles $[8,9,28]$. On the other hand, such cycles do not appear to affect the intact SCN, the central clock of the brain. The SCN itself becomes sensitive to ambient temperature cycles only if communication between its neurons is restricted, as is the case in early development [39] or can be accomplished with application of tetrodotoxin [9]. This is an interesting observation with respect to aging, where communication between SCN neurons is likely to be compromised because of low expression of vasoactive intestinal polypeptide, an essential factor in electrical synchronization of SCN neurons [56]. In humans, the decrease in VIP occurs in a gender-specific way, i.e., in males mostly [77]. Thus, it may be that temperature cycles have the capacity to enhance sleep-wake rhythms more prominently at high age, where rhythms are most vulnerable and associated with well-being [15]. 


\section{Support for an effect of skin temperature on vigilance in humans}

What is, in humans, the observational support for an association between skin temperature and vigilance, operationalized as the ability to initiate or maintain sleep or alert wakefulness? First, constant routine and forced desynchrony studies provide unequivocal observational support that people sleep best while they head towards the trough of their 24-h core body temperature and perform best around its peak [94]. Constant routine protocols fix posture, activity, light, behavioral state, and food intake over a prolonged period of time. These normally give confounding effects because they coincide with transitions between wake and sleep or their preferred circadian phase of occurrence. In forced desynchrony protocols, sleep-wake cycles of more (e.g., $28 \mathrm{~h}$ ) or less (e.g., $20 \mathrm{~h}$ ) than $24 \mathrm{~h}$ are implemented. The endogenous biological clock cannot keep pace with these periods, so that, if continued long enough, effects of its near-24-h rhythms can be deconvolved from the effects of the imposed non-24-h rhythm. Unfortunately, because skin temperature was usually not measured during these studies, the relative contribution of the inversely related core and skin temperature changes to the variance in vigilance could not be evaluated. A number of studies that specifically investigated spontaneous or indirectly experimentally induced fluctuations in skin temperature, however, strongly support an association with vigilance. Healthy people fall asleep more easily if their skin temperature or bed temperature is higher $[47,48,93]$. The same association was shown for people with a vasospastic syndrome, who have a lower temperature of their hands and tend to have difficulties falling asleep [64], and for narcoleptic patients, where skin temperature is correlated to their daytime sleep propensity [32]. With respect to the ability to maintain alert wakefulness, healthy people perform better during the troughs of their normal daytime skin temperature fluctuations [74]. Preliminary findings in both healthy elderly people and demented elderly people also indicate more complaints on daytime sleepiness in those who have elevated daytime skin temperature [60].

Whereas in these studies proximal skin temperature has often been found to predict vigilance measures better than distal skin temperature, controlled laboratory studies suggest the reverse. Based on these controlled studies, it has been proposed that it may especially be the gradient between the temperatures measured at a distal and a proximal site that correlates most strongly with measures of vigilance [46-49]. In these studies, subjects are in a semi-supine position that promotes skin blood flow and results in higher baseline skin temperatures. An important question to address in future research is to what extent mild fluctuations around a lower versus higher baseline skin temperature modify their association with fluctuations in vigilance levels.

All these correlational studies can be interpreted as merely indicating that skin temperature reflects an underlying process of vigilance regulation. What is the experimental support for a causal contribution of skin temperature to vigilance regulation? Controlled skin temperature manipulation studies using a water-perfused thermosuit indeed provide support for the notion that skin temperature modulates vigilance regulation, and more than core temperature does. It has been demonstrated in younger and older healthy adults, as well as in patients suffering from either insomnia or narcolepsy, that very mild skin cooling enhances sustained task performance and the ability to maintain wakefulness [34, 70], while mild skin warming facilitates sleep onset $[67,71]$ and promotes slow wave sleep and sleep maintenance [33, 69]. Skin temperature manipulations may thus even complement available research tools to experimentally affect slow cortical oscillations during sleep $[55,81]$. Concertedly, these findings now provide strong support for a causal contribution of skin temperature to vigilance regulation, as was suggested from animal studies (reviewed in [83]).

The controlled manipulation studies simultaneously and relatively independently manipulated the temperatures of the core, of the distal skin areas (i.e., hands and feet), and of the proximal skin areas (i.e., legs, trunk, and arms). The studies therefore allowed for the conclusion that, within the comfortable thermoneutral range that does not directly trigger thermoregulatory responses, the effect of a proximal skin temperature manipulation is stronger than the effect of manipulating either core temperature or distal skin temperature. Predominance of skin over core temperature effects on the brain makes sense from a survival perspective. Given the fact that the central part of the body is thermally buffered, it would be a disadvantage if an animal would respond only by the time an environmental thermal challenge has affected core temperature. A predominance of skin temperature effects has also been reported with respect to the disrupting effect of body cooling on performance. For example, Cheung et al. [17] administered vigilance and spatial attention tests while subjects were immersed in a cool water bath and reported that all disruptive effects on performance occurred immediately with skin cooling, while performance did not get any worse with the much slower developing decline in core body temperature. Of note, studies like these differ with respect to the applied temperature range. With all our aforementioned studies on manipulation of sleep and vigilance, temperature was only manipulated within the thermoneutral zone, thus not stressful, neither activating thermoregulatory mechanisms to defend temperature. People neither sleep nor perform well at extreme environmental temperatures, 
and sleep versus wake-promoting effects may be restricted to a narrow comfortable temperature range, where the optimal temperature for sleep slightly differs from the optimal temperature to e.g. sustain attention. This is schematically shown in Fig. 1.

\section{Towards practical applications of sleep enhancement}

An important question that ensues from our controlled direct skin temperature manipulation studies using a dedicated water-perfused thermosuit set up in the lab is to what extent they can be applied in daily life. It turns out that a translation towards a practical application is not trivial. Field studies trying to improve sleep with a heating blanket actually show that it disrupts sleep [31]. The most likely reason for this failure is that a heating blanket continues to add heat to the body, thus increasing core body temperature. The situation of an elevated skin temperature while core temperature does not decrease should alarm the thermoregulatory systems of the organism to note that a thermally undesirable and possibly dangerous situation is

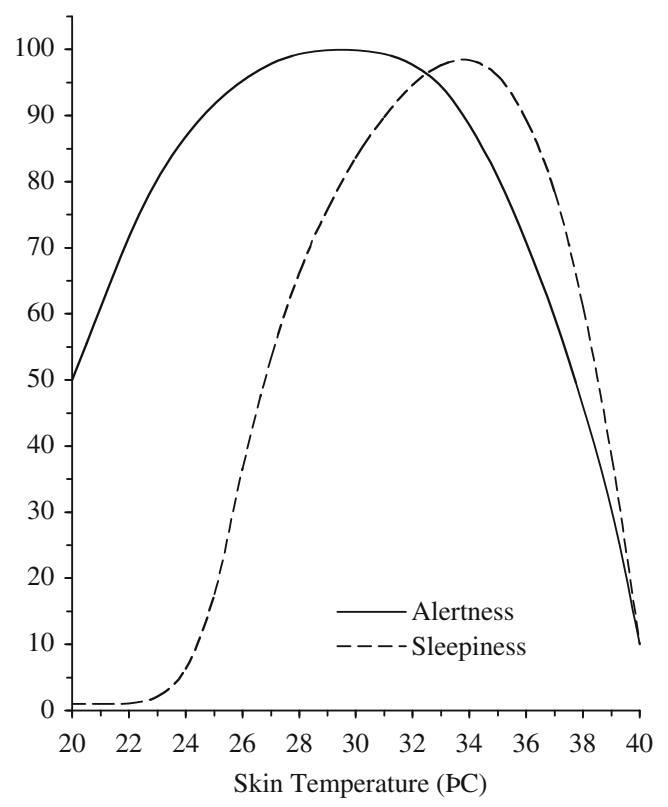

Fig. 1 A schematic representation of how we envision skin temperature may affect sleep and wake propensity regulation. Both the capacity to initiate or maintain sleep or to perform/performance on a sustained attention tasks are compromised at low and high temperatures because the brain will prioritize recruitment of its resources to solve a possibly disadvantageous thermal situation. Within a relatively small comfortable thermoneutral zone, there is no need for the brain to activate thermoregulatory defense mechanisms. Within this range, small differences in skin temperature may promote the brain to reach its peaks of vigilance-promoting and sleep-promoting capacities. It requires only the assumption that the temperature at which the peaks reach their maximum differs slightly for vigilance-promoting and sleep-promoting capacities present, and disrupt sleep in favor of autonomic or behavioral thermoregulatory defense mechanisms. If our rationale is correct, one may argue that only more subtle approaches of direct skin temperature manipulation are likely to produce the desired sleep-promoting effect (Fig. 1).

Surprisingly, within a very small temperature range, it appears theoretically possible to impose a slightly warmer skin temperature, yet promoting rather than inhibiting heat loss and thus lowering skin temperature. In humans, the environmental temperature that the skin is exposed to strongly determines the volume of blood flowing through the skin vasculature, and thus the efficiency of exchanging heat from the body to the environment. The skin is a relatively good insulator, keeping the heat within the body up to an environmental temperature of about $33^{\circ} \mathrm{C}$. However, it dramatically loses its heat-insulating properties and allows for a much more effective heat transfer to the environment once it is exposed to, and takes on, an environmental temperature of $\sim 35^{\circ} \mathrm{C}$ [Fig. 2, 6, 29]. Thus, while the temperature gradient between the core and the environment decreases if the environment is warmed, the possibility to lose heat does not necessarily decrease and may even increase. The large increase in skin blood flow with this small increase in skin temperature effectively reduces the heat insulation properties the skin normally provides, and facilitates heat flow from the core to the

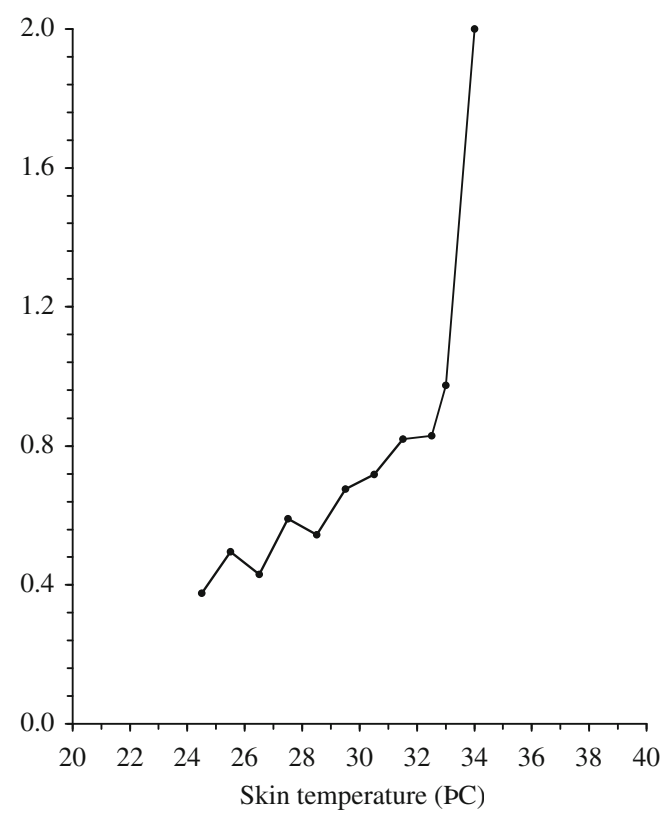

Fig. 2 Correlation between skin temperature and resting blood flow velocity $(\mathrm{CBV})$ in one nailfold capillary of a healthy 37 -year-old man. Notice the marked increase in $\mathrm{CBV}$ occurring at $34^{\circ} \mathrm{C}$. Figure and legend text above are after Fagrell and Intaglietta [30], who investigated the effect of skin warming on skin blood flow. The figure illustrates that warming the skin to at least $34^{\circ} \mathrm{C}$ can dramatically increase skin blood flow and may theoretically improve heat loss to the environment 
environment. Thus, while the gradient between a core body temperature of $37^{\circ} \mathrm{C}$ and an environment of $\sim 35^{\circ} \mathrm{C}$ is less than a gradient of $37^{\circ} \mathrm{C}$ versus $33^{\circ} \mathrm{C}$, it may still be easier to reach lower core body temperatures because the insulating property of the skin is much reduced. Efforts to improve sleep by external heating should obtain feedback from the skin to create a closed loop manipulation, ensuring that it keeps the skin temperature within a range that still allows for the core body temperature to drop-settings which may even differ between individuals. Ultimately, this closed loop manipulation may lead to home-applicable versions of the methodology that showed efficacy in lab studies on young and elderly people without sleep complaints or suffering from insomnia or narcolepsy [33, 67, 69, 71].

Another, indirect, possibility to increase skin temperature during the sleep period without impeding the nocturnal drop in core body temperature is to make use of normal thermoregulatory mechanisms. This alternative to direct warming of the skin during the desired sleep period is to heat the body prior to sleep, for example, by exercising or taking a hot bath or sauna. Body heating activates heat dissipation for a duration that outlasts the heat stress, and consequently may keep skin blood flow higher for a few hours. Indeed, this indirect endogenous skin warming procedure has shown to improve subsequent sleep in several studies (reviewed in [68]). It is important to note that this sleep enhancement seems to occur mostly when the heat stress is annihilated, i.e., core temperature is no longer elevated, while skin temperature is still somewhat increased due to the overshoot in heat dissipation $[10,11$, $20,23-25,40,41,44,45,76]$. Thus, because of the restricted interval of increased sleep propensity, this procedure may be applied to enhance sleep onset and improve sleep in the first hours of the night. But it is unlikely to show an effect on complaints of early morning awakening, which may only be alleviated using direct skin temperature manipulation, as demonstrated in our lab studies [69].

An important question is whether skin temperature control to promote sleep would be necessary at all? If one examines time lapse videos of sleeping humans, it seems evident that people, during brief arousals from sleep, apply behavioral thermoregulation by kicking away the blankets or duvet to expose limbs to the cooler environment alternating with covering oneself to create a warm microclimate. But what if this behavior is somehow compromised? Or what if there is a deficit in the conscious or unconscious evaluation of the most appropriate temperature. It has never been evaluated systematically whether nocturnal thermoregulatory behavior differs between insomniacs and people without sleep complaints. We have an indication, however, that at least some phenotypes of insomnia may not recognize the most comfortable thermal microclimate that is conductive to sleep [71]. Interestingly, these observations were recently supported by our finding [5] that the severity of their sleep complaints correlated with structural abnormalities in the part of the orbitofrontal cortex that is essential for the evaluation of comfort [27, 73].

Skin warming may thus be helpful for some insomnia phenotypes. However, we have unpublished data suggesting that in some insomniacs, metabolic heat production and heat-dissipating mechanisms are both elevated. In this case, further enhancement of heat dissipation may not be possible or useful. Any endeavor to evaluate the application of skin temperature control to promote sleep in insomniacs may thus profit from rigorous phenotype profiling and selection. Since the reliable long-term assessment of skin temperature in field studies has recently become as feasible as actigraphic assessments of sleep-wake rhythms has been for many years $[82,87,90,91]$, it would be of value to assess skin temperature profiles in large cohorts of people with and without sleep complaints. In addition, web-based surveys for multivariate assessment of insomnia phenotypes (www.sleepregistry.org, see [89]) could include extensive questioning on subjective thermosensitivity and behavioral thermoregulation. Concertedly, we estimate that it will be feasible within years to support the sleep of at least a subgroup of insomniacs using mild skin temperature manipulations.

Acknowledgments This research is supported by Project NeuroSIPE 10738, of the Dutch Technology Foundation STW, which is part of the Netherlands Organization for Scientific Research (NWO) and partly funded by the Ministry of Economic Affairs, Agriculture and Innovation.

Open Access This article is distributed under the terms of the Creative Commons Attribution Noncommercial License which permits any noncommercial use, distribution, and reproduction in any medium, provided the original author(s) and source are credited.

\section{References}

1. Achermann P, Dijk DJ, Brunner DP, Borbely AA (1993) A model of human sleep homeostasis based on EEG slow-wave activity: quantitative comparison of data and simulations. Brain Res Bull 31:97-113

2. Aeschbach D, Cajochen C, Tobler I, Dijk DJ, Borbely AA (1994) Sleep in a sitting position: effect of triazolam on sleep stages and EEG power spectra. Psychopharmacology (Berl) 114:209-214

3. Akerstedt T, Kecklund G, Axelsson J (2007) Impaired sleep after bedtime stress and worries. Biol Psychol 76:170-173

4. Alam MN, McGinty D, Szymusiak R (1995) Neuronal discharge of preoptic/anterior hypothalamic thermosensitive neurons: relation to NREM sleep. Am J Physiol 269:R1240-R1249

5. Altena E, Vrenken H, Van Der Werf YD, Van Den Heuvel OAV, Van Someren EJW (2010) Reduced orbitofrontal and parietal grey matter in chronic insomnia: a voxel-based morphometric study. Biol Psychiatry 67:182-185 
6. Barcroft H, Edholm OG (1943) The effect of temperature on blood flow and deep temperature in the human forearm. J Physiol 102:5-20

7. Borbély AA (1982) A two process model of sleep regulation. Hum Neurobiol 1:195-204

8. Brown SA, Zumbrunn G, Fleury-Olela F, Preitner N, Schibler U (2002) Rhythms of mammalian body temperature can sustain peripheral circadian clocks. Curr Biol 12:1574-1583

9. Buhr ED, Yoo SH, Takahashi JS (2010) Temperature as a universal resetting cue for mammalian circadian oscillators. Science 330:379-385

10. Bunnell DE, Agnew JA, Horvath SM, Jopson L, Wills M (1988) Passive body heating and sleep: influence of proximity to sleep. Sleep 11:210-219

11. Bunnell DE, Horvath SM (1985) Effects of body heating during sleep interruption. Sleep 8:274-282

12. Cajochen C, Munch M, Kobialka S, Krauchi K, Steiner R, Oelhafen P, Orgul S, Wirz-Justice A (2005) High sensitivity of human melatonin, alertness, thermoregulation, and heart rate to short wavelength light. J Clin Endocrinol Metab 90:1311-1316

13. Caldwell JA, Prazinko B, Caldwell JL (2003) Body posture affects electroencephalographic activity and psychomotor vigilance task performance in sleep-deprived subjects. Clin Neurophysiol 114:23-31

14. Caldwell JA, Prazinko BF, Hall KK (2000) The effects of body posture on resting electroencephalographic activity in sleepdeprived subjects. Clin Neurophysiol 111:464-470

15. Carvalho-Bos S, Riemersma-van der Lek RF, Waterhouse J, Reilly T, Van Someren EJW (2007) Strong association of the restactivity rhythm with well-being in demented elderly women. Am J Geriatr Psychiatry 15:92-100

16. Charuvastra A, Cloitre M (2009) Safe enough to sleep: sleep disruptions associated with trauma, posttraumatic stress, and anxiety in children and adolescents. Child Adolesc Psychiatr Clin N Am 18:877-891

17. Cheung SS, Westwood DA, Knox MK (2007) Mild body cooling impairs attention via distraction from skin cooling. Ergonomics $50: 275-288$

18. Cole RJ (1989) Postural baroreflex stimuli may affect EEG arousal and sleep in humans. J Appl Physiol 67:2369-2375

19. Daan S, Beersma DG, Borbely AA (1984) Timing of human sleep: recovery process gated by a circadian pacemaker. Am J Physiol 246:R161-R183

20. Di Nisi J, Ehrhart J, Galeou M, Libert JP (1989) Influence of repeated passive body heating on subsequent night sleep in humans. Eur J Appl Physiol 59:138-145

21. Dibner C, Schibler U, Albrecht U (2010) The mammalian circadian timing system: organization and coordination of central and peripheral clocks. Annu Rev Physiol 72:517-549

22. Dijk DJ, Czeisler CA (1995) Contribution of the circadian pacemaker and the sleep homeostat to sleep propensity, sleep structure, electroencephalographic slow waves, and sleep spindle activity in humans. J Neurosci 15:3526-3538

23. Dorsey CM, Lukas SE, Cohen-Zion M, Sterfanovic L (1998) Passive body heating vs. Zolpidem in older female insomniacs. Sleep 21(S3):255

24. Dorsey CM, Lukas SE, Teicher MH, Harper D, Winkelman JW, Cunningham SL, Satlin A (1996) Effects of passive body heating on sleep of older female insomniacs. J Geriatr Psychiatry Neurol 9:83-90

25. Dorsey CM, Teicher MH, Cohen-Zion M, Stefanovic L, Satlin A, Tartarini W, Harper D, Lukas SE (1999) Core body temperature and sleep of older female insomniacs before and after passive body heating. Sleep 22:891-898

26. Drewes AM, Nielsen KD, Arendtnielsen L, Birketsmith L, Hansen LM (1997) The effect of cutaneous and deep pain on the electroencephalogram during sleep - an experimental study. Sleep 20:632-640
27. Dunn BJ, Conover K, Plourde G, Munro D, Kilgour R, Shizgal P (2010) Hedonic valuation during thermal alliesthesia. Abstracts of the 16th Annual Meeting of the Organization for Human Brain Mapping, Barcelona

28. Edery I (2010) Circadian rhythms. Temperatures to communicate by. Science 330:329-330

29. Fagrell B (1985) Dynamics of skin microcirculation in humans. J Cardiovasc Pharmacol 7(Suppl 3):S53-S58

30. Fagrell B, Intaglietta M (1977) The dynamics of skin microcirculation as a tool for the study of systemic diseases. Bibl Anat 16:231-234

31. Fletcher A, van den Heuvel C, Dawson D (1999) Sleeping with an electric blanket: effects on core temperature, sleep, and melatonin in young adults. Sleep 22:313-318

32. Fronczek R, Overeem S, Lammers GJ, Van Dijk JG, Van Someren EJW (2006) Altered skin temperature regulation in narcolepsy relates to sleep propensity. Sleep 29:1444-1449

33. Fronczek R, Raymann RJEM, Overeem S, Romeijn N, Van Dijk JG, Lammers GJ, Van Someren EJW (2008) Manipulation of skin temperature improves nocturnal sleep in narcolepsy. J Neurol Neurosurg Psychiatry 79:1354-1357

34. Fronczek R, Raymann RJEM, Romeijn N, Overeem S, Fischer M, Van Dijk JG, Lammers GJ, Van Someren EJW (2008) Manipulation of core body and skin temperature improves vigilance and maintenance of wakefulness in narcolepsy. Sleep 31:233-240

35. Halasz P (1998) Hierarchy of micro-arousals and the microstructure of sleep. Neurophysiol Clin 28:461-475

36. Hampf G (1990) Influence of cold pain in the hand on skin impedance, heart rate and skin temperature. Physiol Behav 47:217-218

37. Haskell EH, Palca JW, Walker JM, Berger RJ, Heller HC (1981) The effects of high and low ambient temperatures on human sleep stages. Electroencephalogr Clin Neurophysiol 51:494-501

38. Hensel H (1973) Cutaneous thermoreceptors. In: Iggo A (ed) Handbook of sensory physiology, volume II: somatosensory system. Springer, Berlin, pp 79-110

39. Herzog ED, Huckfeldt RM (2003) Circadian entrainment to temperature, but not light, in the isolated suprachiasmatic nucleus. J Neurophysiol 90:763-770

40. Horne JA, Reid AJ (1985) Night-time sleep EEG changes following body heating in a warm bath. Electroencephalogr Clin Neurophysiol 60:154-157

41. Horne JA, Shackell BS (1987) Slow wave sleep elevations after body heating: proximity to sleep and effects of aspirin. Sleep 10:383-392

42. Iannetti GD, Leandri M, Truini A, Zambreanu L, Cruccu G, Tracey I (2004) Adelta nociceptor response to laser stimuli: selective effect of stimulus duration on skin temperature, brain potentials and pain perception. Clin Neurophysiol 115:2629-2637

43. Johnson JM, Kellogg DL Jr (2010) Thermoregulatory and thermal control in the human cutaneous circulation. Front Biosci (Schol Ed) $2: 825-853$

44. Jordan J, Montgomery I, Trinder J (1990) The effect of afternoon body heating on body temperature and slow wave sleep. Psychophysiol 27:560-566

45. Kanda K, Tochihara Y, Ohnaka T (1999) Bathing before sleep in the young and in the elderly. Eur J Appl Physiol 80:71-75

46. Kräuchi K, Cajochen C, Werth E, Wirz-Justice A (1999) Distalproximal skin temperature gradient predicts sleep onset latency. Sleep 22:S286

47. Kräuchi K, Cajochen C, Werth E, Wirz-Justice A (1999) Warm feet promote the rapid onset of sleep. Nature 401:36-37

48. Kräuchi K, Cajochen C, Werth E, Wirz-Justice A (2000) Functional link between distal vasodilation and sleep-onset latency? Am J Physiol 278:R741-R748

49. Kräuchi K, Cajochen C, Wirz-Justice A (1997) A relationship between heat loss and sleepiness: effects of postural change and melatonin administration. J Appl Physiol 83:134-139 
50. Krueger JM, Clinton JM, Winters BD, Zielinski MR, Taishi P, Jewett KA, Davis CJ (2011) Involvement of cytokines in slow wave sleep. Prog Brain Res 193:39-47

51. Lack LC, Gradisar M, Van Someren EJW, Wright HR, Lushington $\mathrm{K}$ (2008) The relationship between insomnia and body temperatures. Sleep Med Rev 12:307-317

52. Lavigne GJ, Zucconi M, Castronovo V, Manzini C, Veglia F, Smirne S, Ferini-Strambi L (2001) Heart rate changes during sleep in response to experimental thermal (nociceptive) stimulations in healthy subjects. Clin Neurophysiol 112:532-535

53. Leemburg S, Vyazovskiy VV, Olcese U, Bassetti CL, Tononi G, Cirelli C (2010) Sleep homeostasis in the rat is preserved during chronic sleep restriction. PNAS 107:15939-15944

54. Lei J, You HJ, Andersen OK, Graven-Nielsen T, Arendt-Nielsen L (2008) Homotopic and heterotopic variation in skin blood flow and temperature following experimental muscle pain in humans. Brain Res 1232:85-93

55. Marshall L, Helgadottir H, Molle M, Born J (2006) Boosting slow oscillations during sleep potentiates memory. Nature 444:610-613

56. Maywood ES, Reddy AB, Wong GK, O’Neill JS, O'Brien JA, McMahon DG, Harmar AJ, Okamura H, Hastings MH (2006) Synchronization and maintenance of timekeeping in suprachiasmatic circadian clock cells by neuropeptidergic signaling. Curr Biol 16:599-605

57. McGinty D, Gong H, Alam N, Shin S, Szymusiak R (2001) Warm-sensitive neurons are co-localized with sleep-active neurons in the preoptic hypothalamus. Sleep 24:S58

58. McGinty DJ, Szymusiak RS (1990) Hypothalamic thermoregulatory control of slow-wave sleep. In: Mancia M, Marini G (eds) The diencephalon and sleep. Raven, New York, pp 97-110

59. Mistlberger RE (2005) Circadian regulation of sleep in mammals: role of the suprachiasmatic nucleus. Brain Res Rev 49:429-454

60. Møst E, Van Someren EJW (2008) Elevated daytime skin temperature in cognitively impaired elderly people. J Sleep Res 17:S185

61. Nakajima Y, Takamata A, Ito T, Sessler DI, Kitamura Y, Shimosato G, Taniguchi S, Matsuyama H, Tanaka Y, Mizobe T (2002) Upright posture reduces thermogenesis and augments core hypothermia. Anesth Analg 94:1646-1651

62. Nicholson AN, Stone BM (1987) Influence of back angle on the quality of sleep in seats. Ergonomics 30:1033-1041

63. Okamoto-Mizuno K, Tsuzuki K, Mizuno K (2005) Effects of humid heat exposure in later sleep segments on sleep stages and body temperature in humans. Int J Biometeorol 49:232-237

64. Pache M, Krauchi K, Cajochen C, Wirz-Justice A, Dubler B, Flammer J, Kaiser HJ (2001) Cold feet and prolonged sleep-onset latency in vasospastic syndrome. Lancet 358:125-126

65. Palca JW, Walker JM, Berger RJ (1986) Thermoregulation, metabolism, and stages of sleep in cold-exposed men. J Appl Physiol 61:940-947

66. Porkka-Heiskanen T, Strecker RE, Thakkar M, Bjorkum AA, Greene RW, McCarley RW (1997) Adenosine: a mediator of the sleepinducing effects of prolonged wakefulness. Science 276:1265-1268

67. Raymann RJEM, Swaab DF, Van Someren EJW (2005) Cutaneous warming promotes sleep onset. Am J Physiol 288: R1589-R1597

68. Raymann RJEM, Swaab DF, Van Someren EJW (2007) Skin temperature and sleep-onset latency: changes with age and insomnia. Physiol Behav 90:257-266

69. Raymann RJEM, Swaab DF, Van Someren EJW (2008) Skin deep: cutaneous temperature determines sleep depth. Brain 131:500-513

70. Raymann RJEM, Van Someren EJW (2007) Time-on-task impairment of psychomotor vigilance is affected by mild skin warming and changes with aging and insomnia. Sleep 30:96-103

71. Raymann RJEM, Van Someren EJW (2008) Diminished capability to recognize the optimal temperature for sleep initiation may contribute to poor sleep in elderly people. Sleep 31:1301-1309
72. Rimm-Kaufman SE, Kagan J (1996) The psychological significance of changes skin temperature. Motiv Emot 20:63-78

73. Rolls ET, Grabenhorst F, Parris BA (2008) Warm pleasant feelings in the brain. NeuroImage 41:1504-1513

74. Romeijn N, Van Someren EJW (2011) Correlated fluctuations of daytime skin temperature and vigilance. J Biol Rhythms 26:68-77

75. Sewitch DE, Kittrell EM, Kupfer DJ, Reynolds CFd (1986) Body temperature and sleep architecture in response to a mild cold stress in women. Physiol Behav 36:951-957

76. Sung EJ, Tochihara Y (2000) Effects of bathing and hot footbath on sleep in winter. J Physiol Anthropol Appl Human Sci 19:21-27

77. Swaab DF, Van Someren EJW, Zhou JN, Hofman MA (1996) Biological rhythms in the human life cycle and their relationship to functional changes in the suprachiasmatic nucleus. Prog Brain Res 111:349-368

78. Tikuisis P, Ducharme MB (1996) The effect of postural changes on body temperatures and heat balance. Eur J Appl Physiol 72:451-459

79. Tononi G, Cirelli C (2006) Sleep function and synaptic homeostasis. Sleep Med Rev 10:49-62

80. Van De Werken M, Gimenez MC, De Vries B, Beersma DG, Van Someren EJW, Gordijn MC (2010) Effects of artificial dawn on sleep inertia, skin temperature, and the awakening cortisol response. J Sleep Res 19:425-435

81. Van Der Werf YD, Altena E, Schoonheim MM, Sanz-Arigita E, Vis JC, De Rijke W, Van Someren EJW (2009) Sleep benefits subsequent hippocampal functioning. Nat Neurosci 12:122-123

82. van Marken Lichtenbelt WD, Daanen HAM, Wouters L, Fronczek R, Raymann RJEM, Severens NMW, Van Someren EJW (2006) Evaluation of wireless determination of skin temperature using iButtons. Physiol Behav 88:489-497

83. Van Someren EJW (2000) More than a marker: interaction between the circadian regulation of temperature and sleep, age-related changes, and treatment possibilities. Chronobiol Int 17:313-354

84. Van Someren EJW (2003) Thermosensitivity of the circadian timing system. Sleep Biol Rhythms 1:55-64

85. Van Someren EJW (2004) Sleep propensity is modulated by circadian and behavior-induced changes in cutaneous temperature. J Therm Biol 29:437-444

86. Van Someren EJW (2006) Mechanisms and functions of coupling between sleep and temperature rhythms. Prog Brain Res 153:309324

87. Van Someren EJW (2007) Improving actigraphic sleep estimates: how many nights? J Sleep Res 16:269-275

88. Van Someren EJW (2010) Doing with less sleep remains a dream. PNAS 107:16003-16004

89. Van Someren EJW, Pollmächer T, Leger D, Espie C, Bassetti C, Riemann D (2009) The European insomnia network. Front Neurosci 3:436

90. Van Someren EJW, Van Gool WA, Vonk BFM, Mirmiran M, Speelman JD, Bosch DA, Swaab DF (1993) Ambulatory monitoring of tremor and other movements before and after thalamotomy: a new quantitative technique. J Neurol Sci 117:16-23

91. Van Someren EJW, Vonk BFM, Thijssen W, Speelman JD, Schuurman PR, Mirmiran M, Swaab DF (1998) A new actigraph for long-term registration of the duration and intensity of tremor and movement. IEEE Trans Biomed Eng 45:386-395

92. Vandekerckhove M, Weiss R, Schotte C, Exadaktylos V, Haex B, Verbraecken J, Cluydts R (2011) The role of presleep negative emotion in sleep physiology. Psychophysiol. doi:10.1111/j.1469-8986.2011.01281.x

93. Weysen TE, Chestakov DA, Raymann RJ (2010) Is the temperature in your bed related to sleep onset? J Sleep Res 19:S332

94. Wright KP Jr, Hull JT, Czeisler CA (2002) Relationship between alertness, performance, and body temperature in humans. Am J Physiol 283:R1370-R1377 